\title{
Gas exchange in the Rygg-Kyvsgaard bubble oxygenator
}

\author{
INGE H. RYGG, THORKILD FREDERIKSEN, AND \\ MOGENS JøRGENSEN
}

From the Department of Thoracic Surgery R, Rigshospitalet, and the Cardiological Laboratory, the Copenhagen County Hospital, Gentofte, Denmark

The Rygg-Kyvsgaard oxygenator employed in extracorporeal circulation (Fig. 1) was designed on the basis of experience gained from experimental operations on dogs (Rygg, Engell, and Kyvsgaard, 1956; Rygg and Kyvsgaard, 1957 ; Gammelgaard, Husfeldt, and Therkelsen, 1957; Rygg and Kyvsgaard, 1958 ; Rygg, 1958). However, in experimental operations the opportunities of assessing its oxygenation and carbon dioxide

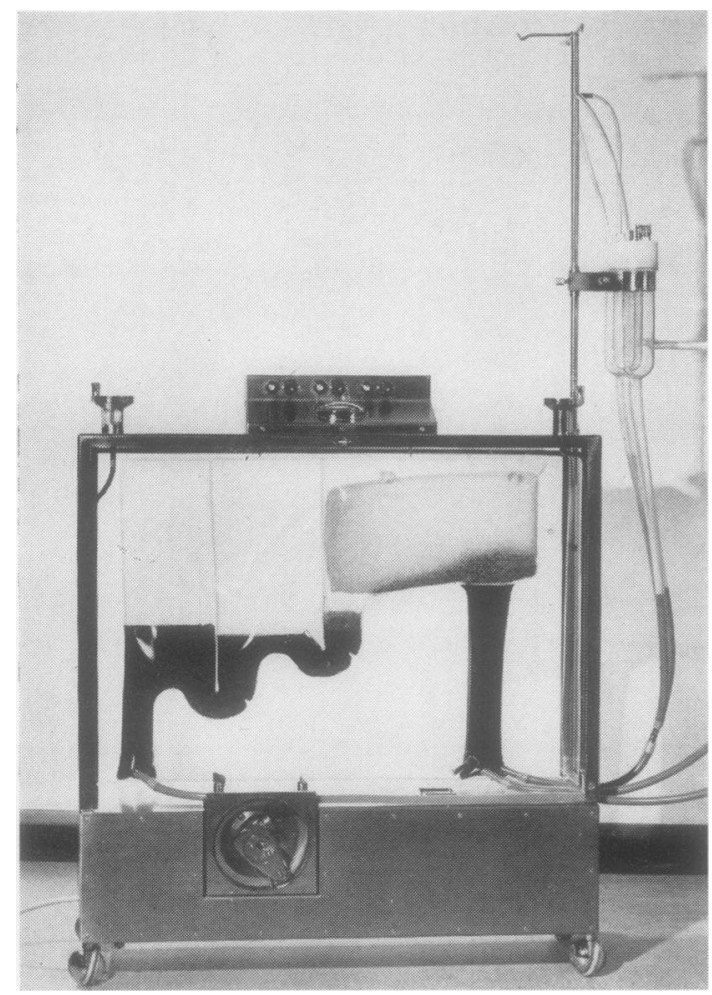

FIG. 1. The Rygg-Kyvsgaard heart-lung machine with the oxygenator containing a priming volume. elimination capacity are limited. Therefore the 은 present study was planned to elucidate these factors on the basis of laboratory experiments.

Details of the apparatus itself, including ease of cleaning, risk of haemolysis, and control of oxygen tension, have already been published (Arnfred, Rygg, Frederiksen, Engell, Poulsen, and Rosen, 1961).

\section{DETERMINATION OF THE OXYGEN UPTAKE CAPACITY}

In these experiments we used freshly drawn ox blood $^{1}$ to which had been added heparin $(100 \mathrm{mg}$. heparin 'Leo' per litre of blood). The oxygen binding capacity of the blood was found to be 17.5 vol. $\%$ determined by oxygenation and subsequent van Slyke analysis of a representative sample. The total amount of blood was 22 litres derived from 11 oxen of the same breed. The entire supply of blood was placed in the desoxygenation chamber (Fig. 2) and bubbled with a mixture of $7 \%$ carbon dioxide and $93 \%$ nitrogen. By means of a surrounding water bath, the temperature of the blood was kept as close to $37^{\circ} \mathrm{C}$. as possible.

In order to obtain a suitable initial oxygen $\circ$ content of the blood, it had to be bubbled with the named gaseous mixture for 10 to 15 minutes before each experiment, the oxygen saturation decreasing only slowly during the bubbling pro- $\sigma$ cedure. In the experiment proper the blood was $N$ pumped from the desoxygenation chamber N through the oxygenator into the reservoir for $\sigma$ oxygenated blood. The oxygen uptake was determined indirectly on the basis of the blood flow through the oxygenator and the difference $\stackrel{\Phi}{?}$ between the oxygen content in the inflowing and the outflowing blood by simple multiplication. The oxygen content of the blood was calculated on the basis of the saturation percentage deter-

${ }^{1}$ Supplied by Leo Pharmaceutical Products, Copenhagen 


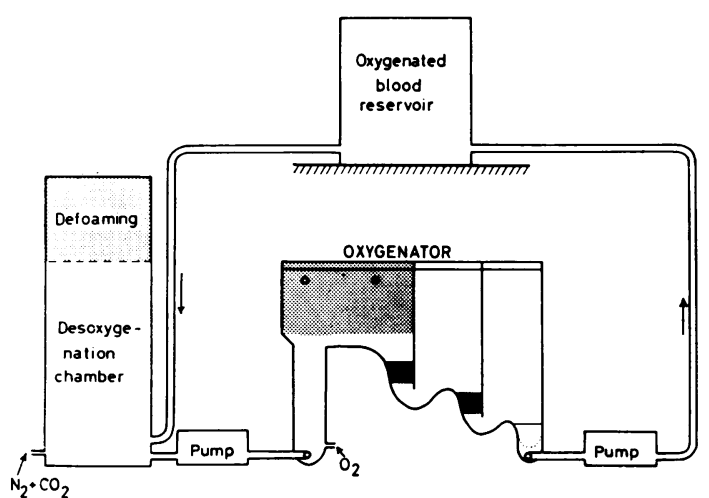

FIG. 2. Experimental set-up in the determination of oxygen capacity.

TABLE I

OXYGEN UPTAKE

\begin{tabular}{lllll}
$\begin{array}{l}\boldsymbol{O}_{2} \text { Flow } \\
\text { (litres) }\end{array}$ & $\begin{array}{l}\text { Blood Flow } \\
\text { (litres) }\end{array}$ & $\begin{array}{l}\text { Pco } \\
\text { (Arterial/ } \\
\text { Venous) }\end{array}$ & $\begin{array}{l}\text { Oxygen } \\
\text { Saturation } \\
\text { (Arteriall } \\
\text { Venous) }\end{array}$ & $\begin{array}{l}\text { Oxygen } \\
\text { Uptake } \\
\text { (ml./min.) }\end{array}$ \\
\hline 3 & & $30 / 66$ & $65 / 40$ & 175 \\
5 & 4 & $65 / 75$ & $70 / 47$ & 161 \\
6 & 4 & $71 / 75$ & $73 / 38$ & 244 \\
6 & 4 & $61 / 73$ & $92 / 59$ & 231 \\
4 & 4 & $64 / 74$ & $87 / 52$ & 245 \\
6 & 4 & $55 / 67$ & $99 / 72$ & 217 \\
4 & $4 \cdot 6$ & $56 / 65$ & $98 / 81$ & 178 \\
3 & 6 & $65 / 69$ & $89 / 70$ & 136 \\
5 & 4 & $59 / 67$ & $94 / 68$ & 182 \\
6 & 4 & $61 / 71$ & $89 / 50$ & 274 \\
4 & 4 & $59 / 71$ & $82 / 50$ & 224 \\
6 & 4 & $62 / 69$ & $75 / 48$ & 283 \\
8 & 6 & $64 / 70$ & $79 / 48$ & 326 \\
2 & 6 & $66 / 70$ & $58 / 36$ & 154 \\
3 & 4 & $67 / 70$ & $59 / 38$ & 147 \\
2 & 4 & $63 / 80$ & $65 / 42$ & 162 \\
3 & 4 & $66 / 73$ & $67 / 45$ & 154 \\
8 & 4 & $60 / 73$ & $81 / 48$ & 346 \\
5 & 6 & $66 / 70$ & $71 / 50$ & 221 \\
& 6 & & &
\end{tabular}

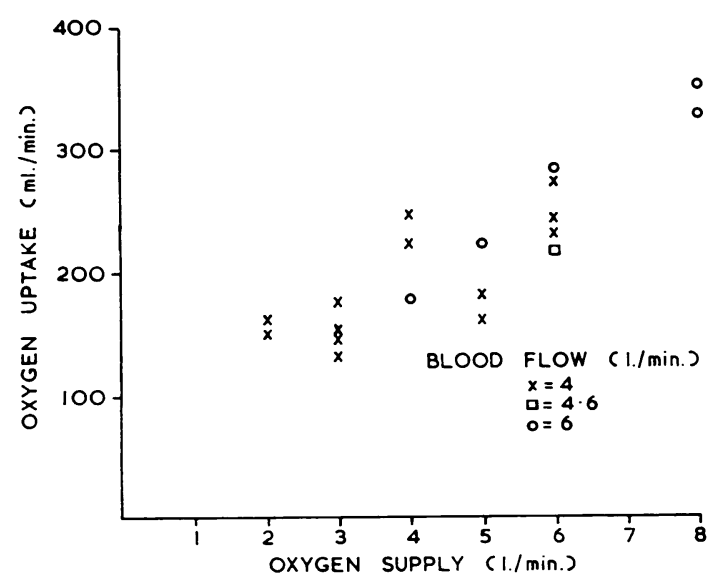

FIG. 3. Relation between supplied amount of oxygen (bubbling) and oxygen uptake of the blood, measured at three different blood flow rates. mined by a haemo-reflectometer (Kipp) and the oxygen capacity of the blood used. In order to avoid errors due to admixture with the blood which was already in the oxygenator before the experiment, the samples were not drawn until an amount of desoxygenated blood as large as possible had passed the oxygenator. In addition to the named samples for determining the oxygen content, we also drew samples for determining the carbon dioxide tension.

A total of 19 experiments was performed. The oxygen uptake was determined partly at varying blood flow through the oxygenator and partly at varying oxygen flow through the oxygenator.

The results are given in Table I which shows that oxygen uptakes up to $346 \mathrm{ml}$./minute were obtained. As is evident from Fig. 3, the oxygen uptake was dependent upon the amount of oxygen used for bubbling, the uptake by the oxygenator being an average of $3 \%$ of the supplied quantity.

\section{DETERMINATION OF THE CARBON DIOXIDE ELIMINATION CAPACITY}

In these experiments we also used freshly drawn ox blood to which was added $100 \mathrm{mg}$. heparin 'Leo' per litre. The circulation of the blood was kept up by a roller pump through two oxygenators and a heat exchanger adjusted to $37^{\circ} \mathrm{C}$. (Fig. 4). In one oxygenator the blood was bubbled with mixtures containing $4 \%$ oxygen and a varying quantity of carbon dioxide. In the other oxygenator the blood was bubbled with $4 \%$

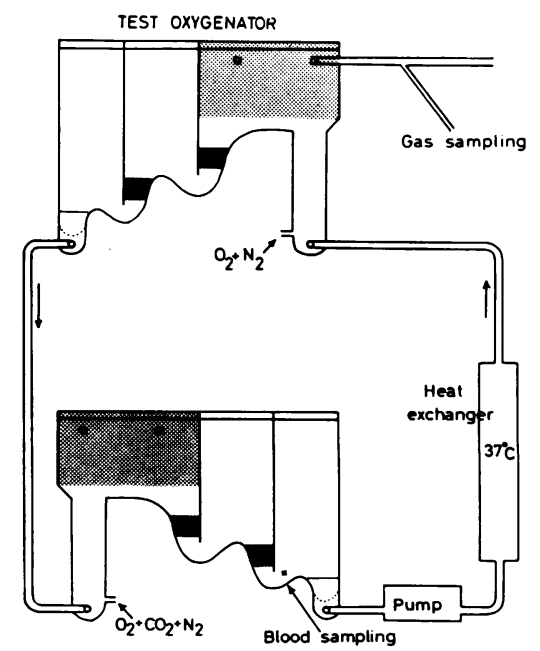

FIG. 4. Experimental set-up in the determination of carbon dioxide elimination. 
oxygen and $96 \%$ nitrogen. After having passed the oxygenator the air was conveyed through a plastic tubing, about $1 \mathrm{~m}$. in length. Through a side tube on its middle, samples were drawn and analysed for their content of carbon dioxide by means of a Scholander gas analysis apparatus (Scholander, 1947). The amount of air used for the bubbling was measured on a calibrated rotameter, and the elimination of carbon dioxide was calculated from the equation:

$$
\left(\mathrm{Vo}+\mathrm{VCO}_{2}\right) \times \mathrm{FCO}_{2}=100 \times \mathrm{VCO}_{2}
$$

where $\mathrm{Vo}$ is the amount of air used, $\mathrm{VCO}_{2}$ the eliminated amount of carbon dioxide, and $\mathrm{FCO}_{2}$ the percentage of carbon dioxide in the outflowing air. A total of 27 experiments was performed in this way. At intervals, the oxygen saturation of the inflowing and outflowing blood was controlled. As might be expected, it fluctuated around $50 \%$.

Table II sets out the results of the carbon dioxide elimination experiments. Carbon dioxide

T A B L E I I $\mathrm{CO}_{2}$ ELIMINATION

\begin{tabular}{|c|c|c|c|c|}
\hline \multirow{2}{*}{$\begin{array}{l}\text { Gas Flow } \\
\text { through Test } \\
\text { Oxygenator } \\
\text { (litres) }\end{array}$} & \multicolumn{2}{|c|}{ Blood Sample } & \multirow{2}{*}{$\begin{array}{l}\mathrm{CO}_{2} \text { in } \\
\text { Gas Sample } \\
(\%)\end{array}$} & \multirow{2}{*}{$\begin{array}{l}\mathrm{CO}_{2} \\
\text { Elimination } \\
(\mathrm{ml} . \mathrm{min} .)\end{array}$} \\
\hline & $\mathrm{pH}$ & $P, o_{2}$ & & \\
\hline $\begin{array}{l}2 \\
2 \\
2 \\
2 \\
3 \\
3 \\
3 \\
5 \\
5 \\
5 \\
5 \\
7 \\
7 \\
7 \\
7 \\
7 \\
6 \\
5 \\
4 \\
3 \\
2 \\
7 \\
6 \\
5 \\
4 \\
3 \\
2\end{array}$ & $\begin{array}{l}7 \cdot 40 \\
7 \cdot 45 \\
7 \cdot 38 \\
7 \cdot 36 \\
7 \cdot 44 \\
7 \cdot 45 \\
7 \cdot 38 \\
7 \cdot 46 \\
7 \cdot 46 \\
7 \cdot 41 \\
7 \cdot 39 \\
7 \cdot 50 \\
7 \cdot 46 \\
7 \cdot 46 \\
7 \cdot 44 \\
7 \cdot 19 \\
7 \cdot 17 \\
7 \cdot 11 \\
7 \cdot 09 \\
7 \cdot 04 \\
6 \cdot 98 \\
7 \cdot 29 \\
7 \cdot 32 \\
7 \cdot 34 \\
7 \cdot 32 \\
7 \cdot 34 \\
7 \cdot 32\end{array}$ & $\begin{array}{r}37 \\
32 \\
37 \\
38 \\
31 \\
30 \\
37 \\
19 \\
25 \\
31 \\
34 \\
23 \\
29 \\
29 \\
31 \\
68 \\
70 \\
85 \\
85 \\
95 \\
127 \\
53 \\
45 \\
42 \\
40 \\
42 \\
40\end{array}$ & $\begin{array}{l}3 \cdot 27 \\
3 \cdot 21 \\
3 \cdot 46 \\
3.42 \\
2 \cdot 47 \\
2 \cdot 54 \\
2 \cdot 32 \\
1 \cdot 78 \\
1 \cdot 94 \\
2 \cdot 10 \\
2 \cdot 18 \\
1 \cdot 23 \\
1.40 \\
1 \cdot 64 \\
1 \cdot 71 \\
3 \cdot 44 \\
3 \cdot 84 \\
4 \cdot 68 \\
5.65 \\
6 \cdot 88 \\
8 \cdot 76 \\
2 \cdot 33 \\
2.45 \\
2 \cdot 70 \\
2.97 \\
3.46 \\
3 \cdot 59\end{array}$ & $\begin{array}{r}65 \\
64 \\
69 \\
69 \\
74 \\
76 \\
70 \\
89 \\
97 \\
105 \\
109 \\
86 \\
98 \\
115 \\
120 \\
241 \\
230 \\
234 \\
276 \\
206 \\
175 \\
163 \\
147 \\
135 \\
119 \\
106 \\
72\end{array}$ \\
\hline
\end{tabular}

eliminations of up to $240 \mathrm{ml}$./minute were achieved. Fig. 5 shows that the elimination of carbon dioxide is dependent on the carbon dioxide tension in the blood supplied to the oxygenator and on the amount of air used for the bubbling. Fig. 6 illustrates the relation between the elimination of carbon dioxide and the air flow through the test oxygenator in six experiments in which the carbon dioxide tension in the inflowing blood ranged from 40 to $50 \mathrm{~mm}$. $\mathrm{Hg}$. In the lastmentioned experimental series an elimination of

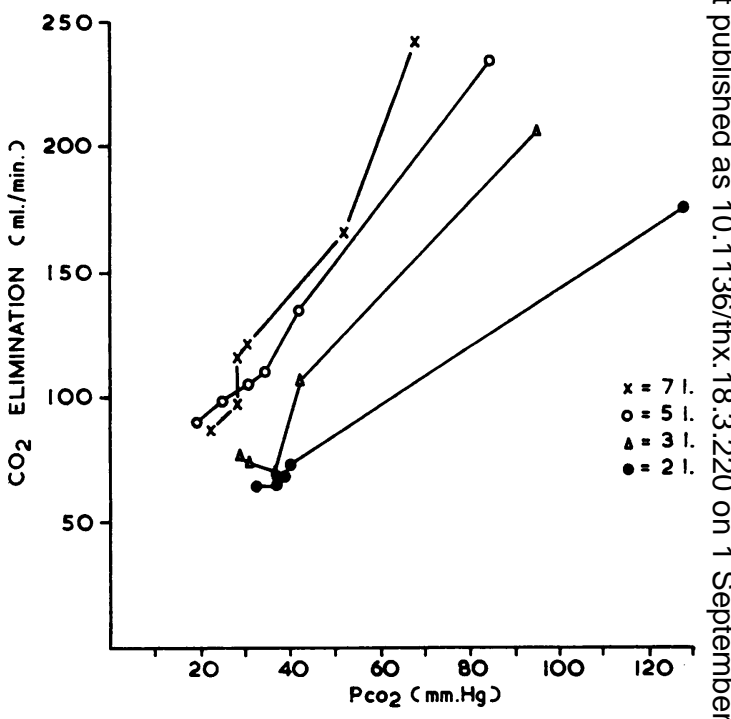

FIG. 5. Relation between carbon dioxide tension in the supplied blood and carbon dioxide elimination per minute, measured at four different gas flow rates.

up to $163 \mathrm{ml}$. carbon dioxide per minute was obtained by an air flow of 7 litres per minute.

\section{DISCUSSION}

To be applicable in extracorporeal circulation an oxygenator, regardless of type and construction, must in the first place be capable of supplying the patient with the amount of oxygen required to maintain the metabolism under the given conditions. In the second place, it must eliminate the carbon dioxide produced by the metabolism.

The application of an oxygenator depends also on whether it can perform these two functions in such a way that the patient can adapt himself to the oxygenator without major shifts in the normal acid-base physiology.

Table I shows that the oxygenator is able to effect an oxygen uptake of more than $300 \mathrm{ml}$. N oxygen per minute, corresponding to an energy $N$ production of over 2,000 calories in 24 hours. An $N$ energy production of this magnitude must be considered in the given circumstances (general anaesthesia) to be appreciably in excess of human requirements.

The capacity of the oxygenator depends, as ?Fig. 3 shows, on the amount of oxygen supplied to it. The figure also shows that the greatest $\frac{\pi}{D}$ oxygen uptakes which were measured necessitated bubbling with 8 litres of oxygen per minute. It 
must be presumed, moreover, that the capacity of the oxygenator is reduced when the affinity of haemoglobin for oxygen has been reduced by a shift in the $p \mathrm{H}$ of the blood into the acid direction caused by increased carbon dioxide tension. As is evident from Table $I$, the experiments were intentionally performed at increased carbon dioxide tensions. If the carbon dioxide tension can be kept down to a normal level, the ability of the oxygenator to take up oxygen must therefore be somewhat greater than that found in the present experiments.

The oxygen uptake which can be measured by laboratory experiments depends on the oxygen saturation in the blood supplied to the oxygenator. If it is high, only a limited quantity of oxygen can be bound chemically in the oxygenator, and a possible excess oxygen uptake ability will result in only a negligible increase in the oxygen uptake in the form of physically bound oxygen. In order to avoid an underestimation of the oxygen uptake ability of the oxygenator, it was necessary to try to obtain such low oxygen saturations in the inflowing blood that the outflowing blood was not fully saturated. It is difficult to anticipate the oxygen uptake, however, and since it is also difficult to 'steer' the desoxygenation procedure the oxygen saturation of the outflowing blood in a number of the experiments was so low that it would not have been accepted as applicable in extracorporeal circulation. Owing to these low values, the mean oxygen tension in the oxygenator is (other things being equal) lower than the mean oxygen tension which would have existed if the blood leaving the oxygenator had been fully saturated. The low initial values favour the oxygen uptake ability of the oxygenator, as it must be presumed that the oxygen uptake is a function of the difference between the oxygen tension in the bubbles and the mean oxygen tension in the blood. It is unlikely, however, that this variation is of more than purely theoretical significance. With pure oxygen, the oxygen tension in the bubbles is around $700 \mathrm{~mm}$. $\mathrm{Hg}$, and the mean oxygen tension in the blood in all the experiments is below $100 \mathrm{~mm}$. Hg. Thus, high and low initial values result in only a slight percentual variation in the named difference. On the other hand, the low initial values of oxygen tension, at which we aimed in order to avoid the risk of a considerable underestimation of the uptake capacity of the oxygenator, hardly entail more than a minimal overestimation of this capacity.

Table II shows that the oxygenator may bring about an elimination of $240 \mathrm{ml}$. carbon dioxide per minute. This also corresponds to an energy production of 2,000 calories/24 hours, providing a respiratory quotient of $0 \cdot 8$. Such a high elimination of carbon dioxide, however, can be obtained only by the use of a large flow of air through the oxygenator, and it presupposes that the carbon dioxide tension in the blood supplied to the oxygenator is considerably higher than it ought to be.

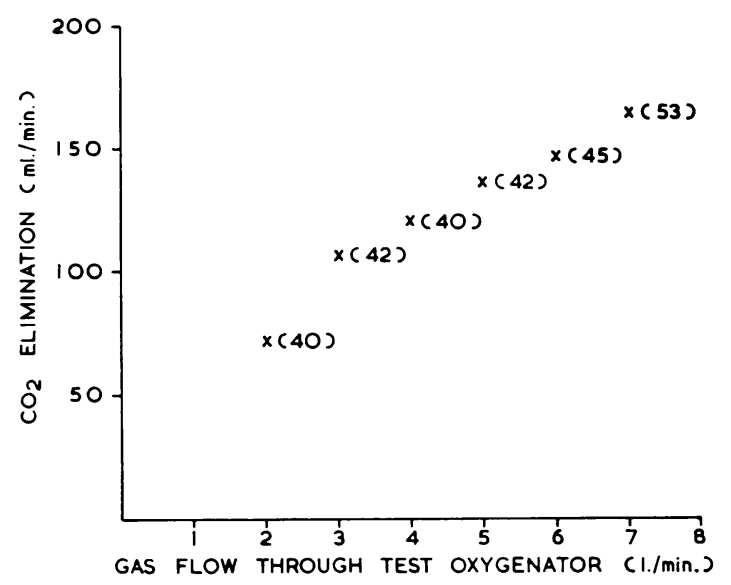

FIG. 6. Relation between gas flow through the test oxygenator and the elimination of carbon dioxide. The figures in brackets indicate the carbon dioxide tension in the inflowing blood.

Fig. 6 illustrates the carbon dioxide elimination ability in a number of experiments in which it was justified to consider the carbon dioxide tension of the blood normal. Since bubbling with air in excess of 7 to 8 litres/minute is hardly practicable, the maximum value of $163 \mathrm{ml} . \mathrm{CO}_{2} /$ minute may be considered the capacity of the oxygenator in the given circumstances. In extracorporeal circulation, however, a somewhat greater carbon dioxide elimination capacity may be expected, as oxygenation of the haemoglobin brings about some reduction in the carbon dioxide binding ability of the blood.

A laboratory reproduction of this process could not be obtained with the present apparatus.

On the basis of the values found in the experiments, the carbon dioxide elimination ability appears to be relatively inferior to the oxygenating capacity of the oxygenator. This is a natural consequence of the fact that the partial pressure differences between blood and bubbles obtainable for oxygen are far higher than the differences obtainable for carbon dioxide. In the latter case, the partial pressure of carbon dioxide in the 
inflowing blood makes up the upper limit of what is attainable.

Our experience so far with the clinical application of the oxygenator suggests that its oxygen uptake and carbon dioxide elimination capacity correspond so well to each other that it is possible to bring about sufficient oxygen uptake without essential shifts in the patient's acid-base physiology (Arnfred et al., 1961 ; Engell, Rygg, Arnfred, Frederiksen, and Poulsen, 1961; Frederiksen, Rygg, and Therkelsen, 1962).

\section{SUMMARY}

The Rygg-Kyvsgaard oxygenator is a disposable bubble oxygenator made of polyvinyl-chloride. Laboratory experiments using ox blood revealed oxygen uptakes up to $346 \mathrm{ml}$./minute. The oxygen uptake was found to depend on the amount of oxygen supplied. Carbon dioxide eliminations of up to $240 \mathrm{ml}$./minute were obtained, and the carbon dioxide elimination was found to depend on the carbon dioxide tension in the inflowing blood and on the amount of air used for the bubbling.
This study was aided by grants from the Danish State Research Foundation and the Arvid Nilsson Foundation.

\section{REFERENCES}

Arnfred, E., Rygg, I. H., Frederiksen, T., Engell, H. C., Poulsen, T., and Rosen, J. (1961). A clinical evaluation of the RyggKyvsgaard III and the Mark III pump oxygenators. Thorax, 16, 309.

Engell, H. C., Rygg, I. H., Arnfred, E., Frederiksen, T., and Poulsen, T. (1961). Clinical comparison between a stationary-screen oxygenator and a bubble-oxygenator in total body perfusion. Acta chir. scand., 122, 243.

Frederiksen, T., Rygg, I. H., and Therkelsen, F (1962). RyggKyvsgaards Herz-Lungenmaschine, Type III. Thoraxchirurgie, 9, 591 .

Gammelgaard, P. A., Husfeldt, E., and Therkelsen, F. (1957). Experimental open heart surgery using a heart-lung machine with a simple disposable oxygenator. Acta chir. scand., 112, 439.

Rygg, I. H. (1958). In Extracorporeal Circulation, ed Allen, J. G., pp. 39-40, 108-110. Thomas, Springfield, Illinois.

, Engell, H. C., and Kyvsgaard, E. (1956). A heart-lung machine with a disposable polyethylene oxygenator system. Dan. med. Bull., 3, 200.

and Kyvsgaard, E. (1957). A disposable polyethylene oxygenator system applied in a heart-lung machine. Acta chir. scand., 112, 433.

(1958). Further development of the heart-lung machine with the Rygg-Kyvsgaard plastic bag oxygenator. Minerva Chir., 13, 1402 .

Scholander, P. F. (1947). Analyzer for accurate-estimation Yof respiratory gases in one-half cubic centimetre_samples. LJ. biol. Chem., 167, 235. 